\title{
1. Introduction: approaching recent transformations of intergovernmental relations from multiple profiles
}

\section{Giorgio Brosio and Juan Pablo Jiménez}

\section{SPECIFICITIES OF THE EVOLUTION OF DECENTRALIZED ARRANGEMENTS IN LATIN AMERICA}

In most Latin American countries, since colonial independence, the shaping of intergovernmental relations has been a crucial component of the debate on the institutional structure of government and constitutional design. In the region, political reform and federalization/decentralization intersect in the political and intellectual debate with an intensity that, possibly, is not observable in other continents.

This is not widely recognized outside Latin America (LA), possibly because the offences by authoritarian rulers and regimes to the federal and decentralized arrangements have been more prominent than the peculiar characteristics and the innovations introduced to them by democratic governments.

There are common characteristics of the decentralization processes worldwide that are worth analyzing from a general and not just a Latin American perspective. At the same time, Latin American countries show some specificities that trace their roots, as to be expected, to the original features of the constitutional and political institutions of the continent.

Decentralization reform has been rapid and intense over the past three decades. Like the rest of the world, most countries in LA have experienced a clear trend towards increasing decentralization of spending responsibilities. As a result, subnational spending rose sharply between 1985 and 2010, both as a ratio to GDP and as a share of overall public sector spending. Subnational governments (SNGs) are managing a much 
larger share of the public sector budget than they did before, although it is not as large as that prevailing in most industrial countries. SNG management is also more active, since most heads of the executive are selected by popular vote due to political decentralization. Following Treisman (2002), LA has one of the highest levels of electoral, that is, political, decentralization.

Decentralization has been especially prominent in health and education expenditures. These two sectors on average account for approximately 40 percent of total subnational spending in the region. In countries such as Argentina, Bolivia (Plurinational State of), Brazil, and Colombia, SNGs are responsible for over 70 percent of total public spending on education, and for 50 percent or more on health. This fact highlights the social implications of a substantial portion of subnational spending in many Latin American countries.

The rapid devolution of spending responsibilities was not mirrored on the revenue side. With the exception of Brazil and, to a much lesser extent, Argentina, Bolivia (Plurinational State of) and Colombia, subnational own revenues in LA account for small, and broadly constant over time, shares of total tax revenues, and for less than 2 percent of GDP, giving rise to large vertical imbalances.

\section{ASYMMETRY BETWEEN DEVOLUTION OF EXPENDITURE AND DEVOLUTION OF TAXING RESPONSIBILITIES}

It is well documented in the relevant literature that this asymmetric trend in decentralization is quite common around the world, but it is especially relevant in LA, and reflects a number of factors (see Ambrosanio and Bordignon, 2006; Ter Minassian and Fedelino, 2010; Gómez Sabaini and Jiménez, ch. 6 in this volume).

First, political economy incentives for both the central government (CG) and most SNGs tend to work in favor of revenue centralization: CGs prefer to maintain control of most revenue bases, and to provide resources to SNGs through transfers and, for their part, SNGs tend to prefer avoiding the political costs of raising resources from their own constituents, and blaming the CG for any shortfall of such resources.

Second, the scope for decentralization of taxing powers is also constrained by economic factors, most notably the higher mobility of goods and factors of production within than outside a national territory. This tends to limit subnational tax handles mainly to property taxes.

Third, with taxing capacities typically being unequally distributed 


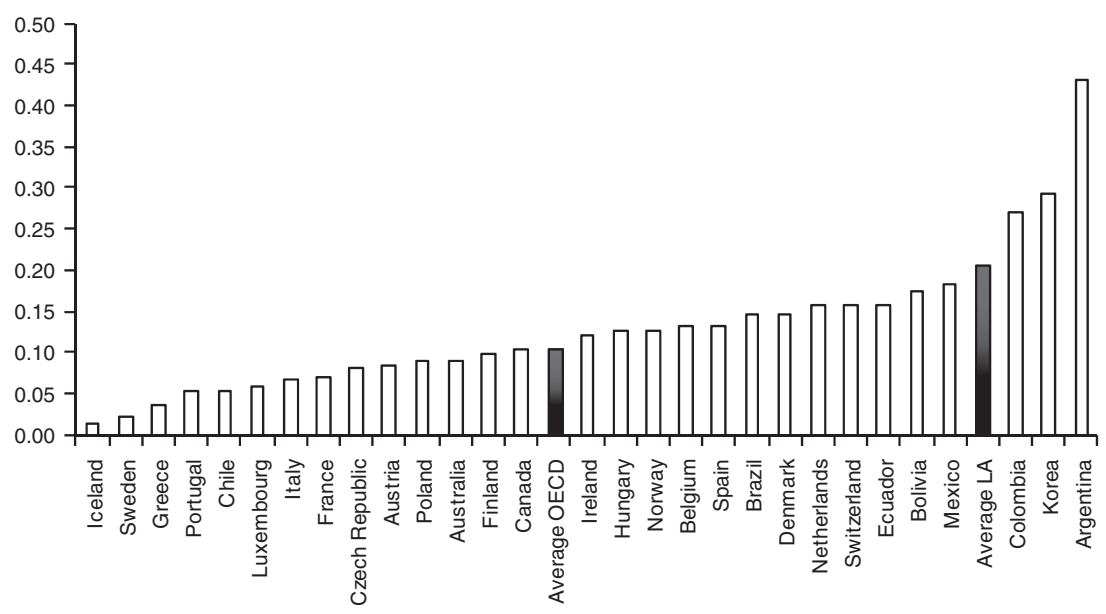

Sources: ECLAC and OECD.

Figure 1.1 Transfer ratio (average 2000-2006) (\% of GDP)

across the national territory (especially in resource-rich countries), significant vertical imbalances need to be maintained between levels of government, to facilitate horizontal redistribution through equalization-type transfers.

In that sense, the growing vertical imbalance is covered by intergovernmental transfers. One important characteristic of LA is the importance of these transfers, which amount to an average of 21 percent - almost double the OECD average (11 percent) (Figure 1.1).

An additional characteristic of the intergovernmental transfer system in LA is the significance of revenue-sharing mechanisms and poorly designed equalization transfer programs (see ch. 9 in this volume).

Finally, subnational tax administrations generally (albeit not always) are less effective than national ones. This is especially evident in LA in the administration of local property taxes, with outdated cadastres (property registers) and infrequent reassessments of property values. As a result, the ratio of property taxes to GDP is equivalent to approximately 20 percent of the corresponding ratio in OECD countries (Gómez Sabaini and Jiménez, ch. 6 and Sepulveda and Martinez-Vazquez, ch. 7 in this volume).

These stylized facts are the results of a long process of reforms during the last three decades that have attracted a lot of analytical attention and have been the focus of considerable academic and expert research in most countries. 


\section{STAGES OF DECENTRALIZATION REFORMS AND THEIR RATIONALE}

In the first period (until the mid-1990s) the leading idea was that decentralization would stimulate more-efficient provision of public goods, and would improve democratic and popular participation and thus accountability. We are referring, in particular, to the constitutional reform in Brazil (1988), to the Coparticipation Law in Argentina (1988), to the decentralization of the health and education law in Argentina (1994) and to the constitutional reform of Colombia (1991).

According to Rezende and Veloso (ch. 8 in this volume) this wave

which gained impetus in the late 1980s, was accompanied by a widespread defense of the virtues of familiarizing governments with their constituencies, so as to improve efficiency in managing public resources, achieve efficacy by adjusting the provision of public services to local priorities, and allowing for the accountability of the governmental authorities. This should also enhance democracy following the demise of authoritarian regimes in some parts of Latin America.

To a large extent the normative theory of fiscal federalism was the intellectual support of these reforms.

At the same time the World Bank - the international organization most active in the support of those reforms - emphasized in a 1988 report:

Decentralization promotes efficiency by allowing a close correspondence between public services and individual preferences, favoring responsibility and equity through a clear relationship between service benefits and costs. This is the justification for the establishment of provincial and local governments sensitive to the wishes of its citizens, and not simply instruments of the central government. (World Bank, 1988, pp. 182-3; see also 1993, pp. 12-13)

Starting from the mid-1990s, and related to some events such as the default in Minas Gerais (Brazil) and the fiscal crisis of Argentina, the process was reoriented. Some governments, experts and international organizations started to worry about the extent of decentralization, and particularly about the increase of subnational debt. The reforms of those days were oriented towards coordinating and controlling subnational borrowing. Most of the fiscal responsibility laws of the region ${ }^{1}$ were formulated in those years to control subnational borrowing.

Questions also started to emerge about the effectiveness of decentralization. In the World Development Report (1997), the World Bank pointed out that decentralization generates significant benefits in different parts of the world, including LA. In particular, it can improve the quality of 
governance and achieve a better representation of citizens. Competition between provinces, cities and localities can spur the development of moreeffective policies and programs. However, the World Bank acknowledges three big potential pitfalls of decentralization: greater inequality, macro instability and submission of local governments to interest groups. The existence of such dangers, then, shows that the role of central governments is vital for the preservation of development: 'The problem is finding the appropriate division of responsibilities between the central and other levels of government' (ibid., p. 13).

\section{PECULIARITIES OF LATIN AMERICAN SOCIETIES AND THEIR CONSTRAINTS ON DECENTRALIZATION}

As mentioned above, the crucial sectors affected by decentralization have been health, education and basic infrastructure. These sectors impact directly on living conditions, particularly of the poor, and have submitted the merits of decentralization to a crucial test. There are some peculiarities of Latin American societies, such as the high inequality in income distribution and territorial disparities which could be considered as a limit or as a justification for the disappointing results noted in some countries. Hence, it becomes very important to check whether and how local institutions have worked in these contexts and to see how their actions can be improved.

As a response to this need, there is a growing branch of the literature that studies the effectiveness of decentralization in terms of service provision. Part of this literature refers specifically to LA (Faguet, 2004; Faguet and Sánchez, 2006). Latin American countries are also included in large sectional studies that analyze the outcomes of decentralization across the world (Robalino et al., 2001; Arze del Granado et al., 2005). According to this literature, there is evidence that substantiates the claims made by the theory that decentralization improves governance by ensuring better preference-matching and allocation efficiency. These findings are partially contradicted by the observation of an increase of poverty and inequality in some Latin American countries in the last part of the 1990s. To a great extent these results have to be assigned to the economic and financial crisis of the end of the decade. They have also impacted on decentralized arrangements. In some countries the need to give a quick response to the deteriorated conditions of the poorest segments of the population has induced the government to introduce new social programs that channel resources directly from the center in a targeted way (Progresa in Mexico; 
Bolsa Familia in Brazil; and the Jefas and Jefes Program in Argentina, among others) (Díaz-Cayeros and Magaloni, 2009).

Institutional changes for social policies are in line with the concomitant and important changes in the economic literature on fiscal federalism with the advent of the so-called 'second generation'. This new literature (Lockwood, 2006; Rodden, 2006; Weingast, 2006) follows the typical political economy approach by replacing the benevolent government assumptions with the more realistic one of self-serving officials and politicians, and stresses the critical role of institutions in determining the effects of centralized or decentralized government.

\section{GROWING MACRO-FINANCIAL CONCERNS ASSOCIATED WITH DECENTRALIZATION}

A growing branch of this recent political economy-based literature focuses on fiscal management. This is not by chance. An increasing number of SNG fiscal crises have ended in most cases with the CG bailout of defaulted units. Macroeconomic policy also constitutes an area where the incentive-based approach to local governance finds an ideal ground for application. Since local governments have little electoral responsibility for macroeconomic performance and since fiscal sovereignty has been concentrated in the hands of the $\mathrm{CG}$, intergovernmental fiscal relations have become a political game where local governments tend to overspend and then ask the CG for financial help once they have exhausted their borrowing capacity. On the other hand, the $\mathrm{CG}$ tries to abstain from intervention, but with a limited credibility deriving from its increased fiscal sovereignty. Quite paradoxically, but not too much in the microeconomic sphere, political incentives increase the efficiency of decentralized government by stimulating competition, while in the macroeconomic sphere they may complicate fiscal and monetary management.

To improve the macroeconomic performance of local governments, the bulk of the literature points to the importance of fiscal institutions, particularly to reliance on taxation instead of $\mathrm{CG}$ transfers. While higher reliance on taxation improves local accountability and hence has a positive, microeconomic, impact on the behavior of SNGs, from a macroeconomic point view things may look different. A high level of fiscal decentralization reached in some countries in the Latin American region is often considered as a factor of fiscal fragility and of amplification of macroeconomic shocks. At the same time, one has to consider that these problems do not necessarily originate in decentralization per se, but rather in underestimation of the need to insert coordination mechanisms 
within the system of intergovernmental relations and of increasing SNG reliance on own taxes.

All these evolutions suggest the need to give new and more emphasis to a wide-spectrum analysis of the working of subnational governance. Studies should range from the empirical analysis of the effective outcomes of decentralization, to the impact of decentralization reforms on equity and poverty and to the macro-financial consequences of devolution of powers and finance.

\section{OVERVIEW OF THE VOLUME}

The aim of the initial seminar that gave birth to the present volume was exactly in line with the exigencies mentioned above. The key issue is not to evaluate the pros and cons of decentralization, but to assess the working of decentralized arrangements and institutions with a view to suggesting corrections and reforms where they are not working according to expectations.

Consideration has been given here to a large set of issues, ranging from the impact of decentralization on social cohesion, to the observable link between decentralization and spending for the social sectors and infrastructure and to the financing of subnational spending responsibilities through taxes, transfers and debt. Special consideration must also be given to macro-financial issues and fiscal rules in view of their relevance in the Latin American context. Additionally, in several countries in the region, the intergovernmental allocation of revenue from natural resources has become one of the most debated issues of the processes of decentralization, bringing the need for careful and multifaceted analysis.

The first topic discussed in this volume is the link between constitutional reform and decentralization. Gargarella and Arballo (ch. 2) describe the context in which constitutional issues have been debated in LA. The authors provide an overview of the present scenario as defined in the latest constitutional reforms in the region, taking into account generally established trends and those just emerging in the area of political and fiscal decentralization. They distinguish between the main federal models that have prevailed in LA and point to a recent process of convergence between them. However, convergence is still limited and refers more to formal than to substantial issues, however important. The authors point out that many crucial issues, such as revenue assignment, are omitted from constitutional texts. This is a reasonable strategy in view of the rapid and changing responses that states have to give to the fast evolution of their socioeconomic and political context impacting on intergovernmental relations. On 
the other hand, this strategy also reflects an uneasiness in making critical choices and may be a source of uncertainty and instability.

Cetrángolo and Goldschmit (ch. 3) take a critical look at decentralization policies in LA that may have had an adverse impact in terms of social cohesion. Based on the existing literature, they evaluate the effects on social cohesion of public policies on decentralization and contemplate the types of reforms needed to achieve greater social cohesion within a decentralized policy environment. Their analysis highlights the importance of taking into account the complex web of interrelated policy objectives, and focuses on a new wave of reforms based on the redefinition of the relevant sector policies. The discussion begins with a brief overview of the way in which decentralization has taken place in LA, the inroads that have been made and the reasons why these processes have been undertaken. The chapter then addresses the tensions and constraints in terms of greater social cohesion that are associated with these reforms, given their effects on fiscal correspondence and solvency. After exploring a few options for easing these tensions, the authors evaluate their impact and provide a number of policy recommendations.

Afonso, Dain, Almeida, Castro and Faveret (ch. 4) focus on the issue of social policies. They examine the evolution and the assignment of social spending in LA, focusing on the perspectives and the main approaches in the current debate on the decentralization of social spending in the region and on the potentiality of fiscal decentralization as an instrument to foster social spending. They note a general increase in social spending in the region and a less general attempt to provide social services on a universal basis. Differences between individual countries are still important and are dominated to a large extent by the level of economic development.

De Mello (ch. 5) analyzes investment in infrastructure - a crucial component of subnational spending - and provides empirical evidence on the effects of decentralization on investment with reference to a panel of countries for which data on this investment are available. The analysis suggests that decentralization discourages Latin American SNGs from investing (acquiring fixed assets) and that lower subnational spending on investment is associated with lower economy-wide gross fixed capital formation. This finding challenges some conclusions of the existing literature stressing the positive impact of decentralization on investment expenditure. According to de Mello, Latin American countries will therefore need to face the double challenge of having to revisit the current arrangements for decentralized provision that discourage SNG investment, while making the most of decentralization as a policy lever to raise private investment.

Gómez Sabaini and Jiménez (ch. 6) examine the assignment of revenue to SNGs and illustrate the main characteristics of financing systems, such 
as vertical imbalance and the prevalence of coparticipation schemes. They analyze the working of SNG financing systems, giving particular attention to the distinct components of subnational own resources. The authors also examine the range of borrowing options available to lower levels of government, as a complement to the 'above-the-line' revenues. The study of specific cases is designed to spotlight the different own-revenue options open to these jurisdictions (intermediate and/or local governments) despite the predominance of CG transfers - as well as the main courses of action that could be taken to strengthen subnational financial autonomy.

In their first contribution to this volume, Sepulveda and MartinezVazquez (ch. 7) focus on the property tax, the most important source of own revenues for local governments around the world. An increasing number of countries that have recently embarked on a decentralization process also look to the property tax as the main vehicle to provide their SNGs with revenue autonomy. In the case of LA, in particular, the property tax continues to be a predominant policy concern among policy makers. However, with very few exceptions, Latin American countries have not been able to develop revenue-productive property tax systems. The region has been identified in the economics literature generally as one with relatively low general tax effort, and with a level of tax performance that is even lower than other developing and transition countries. The issues of low effort and revenue performance are especially acute and challenging in the case of the property tax. The authors analyze the causes of the poor tax performance of the property tax in LA and identify policies that could help with the current impasse

Intergovernmental transfers are the focus of two distinct chapters. Rezende and Veloso's contribution (ch. 8) illustrates the main characteristics exhibited by the transfer regimes of eight Latin American countries, highlighting the changes provoked by reactions to the economic crisis of the 1990s and pointing out their main flaws. They point to the need to improve the efficiency and equity content of the present transfers system and advance a number of propositions concerning the reform of these systems with a view to removing their flaws and making them compatible with both microeconomic and macroeconomic concerns. More specifically, transfer systems have to be more equitable and efficient. At the same time, they have to be flexible to accommodate changes in fiscal policies that can be necessitated by the short-term evolution of macroeconomic conditions.

In their second contribution to this volume, Martinez-Vazquez and Sepulveda (ch. 9) focus on the equalization impact on and the capacity to stimulate own revenue in the present transfer system in nine Latin American countries. Their analysis shows that on both counts substantial 
improvements are needed. Countries in LA might achieve great benefits by reducing their reliance on revenue-sharing schemes and improving the design of equalization transfer programs, with a view to reducing fiscal disparities, and at the same time providing SNGs with the right incentives to expand own revenues and to develop their own tax collection capacity.

Brosio and Jiménez (ch. 10) analyze the allocation of rents from nonrenewable natural resources, hydrocarbons and minerals, among levels of government in LA. This is a crucial issue not only from the point of view of ensuring good governance at the subnational level, but also from the necessity of avoiding political conflict and strains on national unity. Bearing that in mind, the authors first explore the issues connected to the sharing of rents from natural resources among levels of government. This analytical, but policy-oriented section provides a number of policy indications on how to share the rents that are based on the economic theory of factor production remuneration. Second, the authors analyze empirically the issue of intergovernmental sharing in eight Latin American countries endowed with oil, gas and minerals.

The decentralization of spending responsibilities has created growing challenges for macro-fiscal management. On the one hand, it has become more important and more difficult to ensure that SNGs do not accumulate unsustainable debts; on the other, the traditional fiscal federalism's view that short-term macroeconomic stabilization should be the exclusive purview of the CG is becoming increasingly unrealistic.

Jiménez and Ter-Minassian (ch. 11) contribute to this debate on how fiscal decentralization affects macroeconomic management in the main Latin American countries and on the selection of reforms in the existing intergovernmental fiscal systems of those countries that could help to strengthen their fiscal sustainability, minimize the risk of pro-cyclicality at all levels of government, and create 'fiscal space' for active countercyclical responses to economic shocks.

Grembi and Manoel (ch. 12) provide a critical review of the fiscal rules at the subnational level for Argentina, Brazil, Colombia, and Mexico. Innovating on this topic, they provide disaggregated evidence for a sample of countries. This evidence allows some elements to be addressed that deserve further investigation. For instance, in some cases there seems to be no difference between those SNGs that did adopt fiscal rules and those that did not adopt them, whereas in other cases the imposition of the rules from the CG appears to generate compliance, but not change in the fiscal outcomes. Whether the ineffectiveness of the rules is due to their characteristics rather than a weak definition of the decentralization system remains an open issue. Although it is not possible to evaluate the causal impact of the introduction of fiscal rules at the subnational level in the countries of 
reference, the analysis of descriptive statistics shows that a unique indicator of compliance might be a misleading indicator of fiscal rules at that level.

Finally, Ahmad (ch. 13) analyzes the intergovernmental reforms in LA, establishing some stimulating links with 'Asian transplants' and focusing on the role played by international and donor agencies. The chapter distinguishes, in particular, between the normative and the political economy approaches to decentralization, and suggests how excessive reliance on the former had led to inconsistencies in the formulation of policy recommendations by international organizations and the donor community. The chapter also refers to the main recent developments in theoretical literature, singling out the steps that are needed to ensure that the objectives of constitutional reforms are met efficiently.

The editors are confident that the topics analyzed in this book and the issues they raise will have an important impact on the political, social and intellectual life in LA, and contribute to the debate on the reform of intergovernmental relations systems.

\section{NOTE}

1. Usually accompanied by a subnational restructuring debt (Argentina, Brazil and Colombia).

\section{REFERENCES}

Ambrosanio, M.F. and M. Bordignon (2006), 'Normative versus positive theories of revenue assignments in federations', in E. Ahmad and G. Brosio (eds), Handbook of Fiscal Federalism, Cheltenham, UK and Northampton, MA, USA: Edward Elgar, pp. 306-38.

Arze del Granado, Javier, Jorge Martinez Vasquez and Robert McNab (2005), 'Fiscal decentralization and the functional composition of public expenditure', Working Paper 05-01, Andrew Young School of Policy Studies, Georgia State University, Atlanta, GA.

Díaz-Cayeros, Alberto and Beatriz Magaloni (2009), 'Poverty, inequality and democracy', Journal of Democracy, 20 (4), October, 21-35.

Faguet, Jean Paul (2004), 'Does decentralization increase government responsiveness to local needs?', Journal of Public Economics, 88, March, 667-93.

Faguet, Jean Paul and Fabio Sanchez (2006), 'Decentralization's effect on educational outcomes in Bolivia and Colombia', Working Paper, Suntory and Toyota International Centre for Economics and Related Disciplines, London School of Economics and Political Science.

Lockwood, Ben (2006), 'The political economy of decentralization', in E. Ahmad and G. Brosio (eds), Handbook of Fiscal Federalism, Cheltenham, UK and Northampton, MA, USA: Edward Elgar, pp. 33-60. 
Robalino, David, Oscar Picazo and Albertus Voetberg (2001), Does Fiscal Decentralization Improve Health Outcomes? Evidence from a Cross-Country Analysis, World Bank Country Economic Department Series 2565, Washington, DC: World Bank.

Rodden, Jonathan (2006), 'The political economy of federalism', in Barry Weingast and Donald Wittman (eds), Oxford Handbook of Political Economy, Oxford: Oxford University Press, pp. 357-70.

Ter-Minassian, T. and A. Fedelino (2010), 'Impact of the global crisis on subnational governments' finances', in IEB, Fiscal Federalism Report, Institut d'Economia de Barcelona, Barcelona.

Treisman, Daniel (2002), 'Defining and measuring decentralization: a global perspective', Working Paper, University of California Los Angeles, CA.

Weingast, Barry R. (2006), 'Second generation fiscal federalism: implication for decentralized democratic governance and economic development', Working Paper, Hoover Institution, Stanford University, CA.

World Bank (1988), World Development Report 1988, World Bank: Washington, DC.

World Bank (1993), World Development Report: Investing in Health 1993, World Bank: Washington, DC.

World Bank (1997), World Development Report: The State in a Changing World, World Bank: Washington, DC. 